\title{
INTERCULTURALIDADE EM THAT DEAF GUY Uso de Tiras Para Problematização de Estereótipos e Preconceitos Contra Sujeitos Surdos e sua Língua de Sinais
}

\author{
Giselly dos Santos Peregrino ${ }^{1}$ \\ Alessandra Gomes da Silva²
}

\begin{abstract}
RESUMO
As tiras em quadrinhos "That Deaf Guy", de Matt Daigle e Kay Daigle, operam com a interculturalidade para problematizar estereótipos e preconceitos contra as pessoas surdas e a língua de sinais a partir do viés do próprio sujeito da experiência e do humor como estratégia para a desconstrução de ideias preestabelecidas e não ressignificadas. Defende-se, pois, a importância do uso desses textos na escolarização de alunos surdos e não surdos para que possam ter contato com outras formas de representação da surdez para além da esfera da deficiência, encaminhando para o reconhecimento das diferentes formas de vivenciar a condição surda.
\end{abstract}

Palavras-chave: Aquele cara surdo. Surdez. Preconceito. Interculturalidade.

INTERCULTURALITY IN THAT DEAF GUY:

USING STRIPS FOR PROBLEMING STEREOPS AND PREJUDICE AGAINST DEAF SUBJECTS AND THEIR SIGN LANGUAGE

\begin{abstract}
The comics "That Deaf Guy", by Matt Daigle and Kay Daigle, operate with interculturality to problematize stereotypes and prejudices against deaf people and the sign language, from the bias of the subject of experience itself and the humor as a strategy for the deconstruction of pre-established and non-resignified ideas. The importance of the use of these texts in the schooling of deaf and non-deaf students is there fore defended so that they may have contact with other forms of deafness representation, beyond the disability sphere, leading to the recognition of different ways of experiencing deafness.
\end{abstract}

Keywords: That deaf guy. Deafness. Prejudice. Interculturality.

Recebido em: 20/9/2018

Aceito em: 4/4/2019

\footnotetext{
${ }^{1}$ Pós-Doutoranda em Literatura, Cultura e Contemporaneidade na Pontifícia Universidade Católica do Rio de Janeiro (PUC-Rio). Doutorado em Ciências Humanas - Educação pela PUC-Rio (2011/2015). Mestrado em Letras - Estudos de Literatura Brasileira pela PUC-Rio (2008/2010). Licenciatura plena em Letras - Português/Literatura pela Universidade do Estado do Rio de Janeiro (Uerj, 2004/2007). Especialização em Educação de Jovens e Adultos (2009/2010), em Educação Especial/Inclusiva: Deficiência Auditiva/Surdez (2011/2013) e em Alfabetização e Letramento (2018/2019). Professora de Educação Básica, Técnica e Tecnológica - Português/Literatura no Instituto Nacional de Educação de Surdos (Ines). gisellyperegrino@globo.com

2 Doutoranda no Programa de Pós-Graduação em Literatura, Cultura e Contemporaneidade da PUC-Rio. Mestrado pelo mesmo Programa (2016). Graduação em Letras (português-francês) e suas respectivas Literaturas (Bacharelado e Licenciatura) pela Universidade Federal do Rio de Janeiro (2009). Professora de Ensino Básico e Educação Tecnológica do Instituto Nacional de Educação de Surdos, atuando nas áreas de Ensino, Pesquisa e Extensão. Possui, desde 2010, o certificado de proficiência no Uso e no Ensino da Libras (Prolibras). Atuou em cursos de aperfeiçoamento e especialização, nas áreas de Letras e Educação de Surdos. http://lattes.cnpq.br/4611364386568362. https://orcid. org/0000-0003-3129-9802. aletrasufrj@gmail.com
} 
Sabemos que na história da civilização, modos e práticas de narrar são utilizados para comunicar a experiência. Grupos e sujeitos lutam para alterar a forma de participação nas histórias e legitimar discursos sobre si e sobre os outros. Pela palavra, construímos formas de ser e de pensar. Benjamin (1996), em "O narrador. Considerações sobre a obra de Nikolai Leskov", comenta que a dificuldade de narrar consiste na perda da possibilidade de transmitir uma experiência. O filósofo, longe de decretar o fim da arte narrativa, constata que haverá uma mudança nos modos de contar histórias não mais baseadas em experiências, agora incapazes de transmissibilidade, e também não mais por meio de uma figura exemplar ou de um conselho. Não existe mais a crença nessa figura que seja representativa da tradição. Em um mundo de mudanças vertiginosas, a tradição esfacela-se; não há sentido pleno, não há recepção passiva do leitor. Há um plural de histórias em grande diversidade de temas e de contadores. Forçam passagens grupos antes silenciados, e, na luta pela palavra e pelo lugar de fala e na busca por legitimação, eles querem também contar as próprias histórias.

Nessa esfera, visamos a compreender como a produção cultural dos sujeitos surdos vem se intensificando e buscando espaços de fala em meio a representações alheias. Durante muito tempo os sujeitos surdos foram considerados exclusivamente aqueles a quem falta algo - a audição -, desconsiderando-se outras formas de existir no mundo e vivenciar a condição surda. Não havia sequer a legitimação, o reconhecimento e a validação social da Língua Brasileira de Sinais (Libras) como verdadeiramente uma língua. Desse modo, deter-nos-emos nas tiras em quadrinhos nomeadas "That Deaf Guy" ${ }^{3}$ como fonte de problematização dos estereótipos e preconceitos contra os sujeitos surdos e a língua de sinais.

Embora não seja nosso objetivo, neste artigo, explorar as nuances formais das tiras, vale lembrar que elas têm formato, geralmente horizontal, com poucos quadrinhos, nos quais o autor apresenta uma pequena história fechada, com humor normalmente. Linguagens verbal e não verbal entrelaçam-se e são igualmente importantes em tiras, mas podem existir quadrinhos sem palavras, balões, onomatopeias, etc. Jamais há tiras sem linguagem, entretanto. Em "That Deaf Guy" não vemos frequentemente o uso de balões para as falas dos personagens, porém aparecem metáforas visuais, como lâmpadas, por exemplo, com alguma frequência, bem como linhas que indicam a sinalização acontecendo pelas mãos dos que usam a língua de sinais.

Discutiremos como esses artefatos, construídos pelo sujeito que experiencia a surdez, viabilizam e visibilizam uma produção crítico-reflexiva da condição surda e do que pode estar atrelado a ela.

\section{PRESSUPOSTOS TEÓRICOS}

Para problematizar a interculturalidade nos quadrinhos "That Deaf Guy", bem como os estereótipos e preconceitos contra os sujeitos surdos e a língua de sinais, faz-se necessário esclarecermos os conceitos com que estamos operando.

\footnotetext{
${ }^{3}$ Tradução das autoras para o título em inglês "That Deaf Guy": "Aquele Cara Surdo". Disponível em: http://www. thatdeafguy.com. Acesso em: 18 set. 2018.
} 
A interculturalidade, no que diz respeito ao contexto educacional, está orientada à sociedade democrática, plural e humana, articulando políticas de igualdade com políticas de identidade (CANDAU, 2005), supondo a inter-relação entre diferentes grupos socioculturais. Trata-se de um enfoque que afeta a educação em todas as suas dimensões, favorecendo uma dinâmica de crítica e autocrítica, valorizando a interação e a comunicação recíprocas (CANDAU, 2010).

Nesse contexto, a interculturalidade supõe ainda a problematização e a desconstrução de estereótipos e preconceitos, termos que não são sinônimos. Por um lado, o estereótipo é economia cognitiva resultante de processos de simplificação característicos do senso comum (JODELET, 2013) e também é matéria-prima e expressão de um preconceito já engessado em imagens ou expressões verbais, tratando-se de um mecanismo generalista e equivocado do pensamento coletivo e individual (DORTIER, 2010). Por outro lado, o preconceito é uma construção repassada socioculturalmente, podendo ser uma opinião, postura ou crença que se manifesta, podendo originar, assim, a discriminação ou a intolerância. O preconceito é caracterizado por uma ausência de exame crítico em relação ao que se pensa, opina, faz ou acredita. Trata-se de juízos passados e não reexaminados; daí que se torna perigoso (ARENDT, 2012).

Peregrino $(2015,2018)$ argumenta que o preconceito contra sujeitos surdos é uma realidade em pleno século 21 , mesmo havendo larga defesa da inclusão socioeducacional desse público. Defende que é um preconceito com contornos próprios, diferenciando-se de outras facetas do fenômeno. Para a pesquisadora, o preconceito contra surdos recai sobre um estigma que se visibiliza quando do uso da língua de sinais, de modalidade visuoespacial, diferente, pois, daquela em que o preconceito normalmente se torna expresso verbalmente, ou seja, a língua hegemônica, de modalidade oral-auditiva (no nosso caso, a língua portuguesa). Ademais, o preconceito contra surdos pode passar despercebido em discursos arraigados de comiseração e de palavras politicamente corretas ou disfarçados em piadas ou supostas brincadeiras, as quais podem não ser totalmente compreendidas pelo alvo do preconceito (PEREGRINO, 2015, 2018).

Maher (2007), ao abordar a questão da educação linguística-cultural com foco em grupos minoritários, tais como pessoas surdas e indígenas, ressalta a relevância de se observarem alguns aspectos inerentes ao processo. Para ela, os principais são três: uma necessidade de politização do próprio grupo, fundamental para a busca de seus direitos, uma legislação favorável a esses sujeitos e a chamada educação do entorno, visando a um respeito às diferenças. A autora segue argumentando que, sem uma educação do entorno, tornar-se-á difícil, para os grupos minoritários, conseguirem efetivamente exercer sua cidadania. Falta, assim, um maior esclarecimento para que a sociedade possa, de fato, atender às suas demandas. Com base no contexto dos surdos, podemos afirmar que tais demandas levam em conta uma valorização da língua de sinais em diferentes contextos e a compreensão de que ela perpassa o cotidiano escolar; nesse sentido, devem ser levadas em consideração em todas as etapas do processo de ensino/aprendizagem desses alunos; assim, longe de promover um olhar assistencialista para esses sujeitos, busca-se tornar o processo mais justo para esse alunado. Ainda de acordo com 
Maher (2007), estamos distantes do que seria realmente um diálogo intercultural. Muitas vezes negligenciamos as diferenças afastando tudo o que pode parecer dissonante e conservando-nos nas mesmas matrizes culturais.

Por tudo isso, discutir como estereótipos e preconceitos são postos em xeque em tiras em quadrinhos pensadas e confeccionadas pelo próprio sujeito surdo, é dar visibilidade ao modo como esses fenômenos são percebidos, não raro colocando em contraste duas modalidades diferentes de língua: visuoespacial (língua de sinais americana, língua brasileira de sinais, etc.) e oral-auditiva (língua inglesa, língua portuguesa, etc.).

Para pensar a produção cultural de surdos em diálogo com outras produções, como a literatura de reconhecimento e a de testemunho - muito utilizadas pelos grupos minoritários -, buscamos o trabalho de Patrocínio (2013), que, ao analisar a produção literária de autores ditos marginais ou periféricos, destaca duas características dessas obras: a forma identitária e o teor testemunhal. Acreditamos que isso também esteja presente na produção dos surdos, uma vez que tais sujeitos, sobretudo os usuários da língua de sinais, não escapam de uma lógica periférica, das margens, tentando obter visibilidade e dar voz a um grupo minoritário. Nesse sentido, também utilizam a literatura e as demais manifestações culturais, sobretudo audiovisuais, como "veículo de um discurso político formado no desejo de autoafirmação" (PATROCÍNIO, 2013, p. 12). Com isso, empregamos, ainda, o sentido do termo "testemunho" como uma possibilidade de vislumbrar um relato de alguém que vivencia dada realidade, ou seja, o próprio surdo.

Percebe-se que há, também, uma tentativa de autoafirmação e opção por retratar esteticamente temas de interesse do grupo que se representa. Essas manifestações advogam uma necessidade de reconhecimento de outras formas de se narrar que fujam aos estereótipos normalmente empregados com esses sujeitos. No caso do surdo, tais expressões quase sempre abordam temas como a questão da proibição da língua de sinais, a dificuldade de comunicação entre surdos e ouvintes, entre outros. Vale a ressalva de que a lei que legitima a Libras em todo o território brasileiro conta com quase duas décadas de existência (lei no 10.436 de 24 de abril de 2002). Apesar de não ser tão recente quanto parece, ainda há muita mobilização política para que essa legislação seja efetivada nas diferentes esferas sociais, tais como educação, saúde, políticas públicas, acessibilidade cultural, entre outras.

Para Silva (2016), pode-se perceber o crescente interesse de pesquisadores em observar elementos presentes em produções que afastam os indivíduos surdos de uma visão clínico-terapêutica, de cunho positivista, que os considerava predominantemente portadores de uma "doença", o que justificaria sua reabilitação. Desse modo, tal concepção dialoga com diversos profissionais que também buscam, em outras esferas, seja política, seja educacional, uma mudança para a compreensão das pessoas surdas como um grupo que se apresenta com um meio de comunicação próprio - a língua de sinais. Nota-se aí uma confluência nítida entre expressões artísticas e manifestações políticas. 
Para Bauman (2008), organizador da coletânea americana "Deaf Studies" (Estudos Surdos), uma vez questionado o paradigma clínico, torna-se necessário produzir um corpo de conhecimentos sobre os Surdos, ${ }^{4}$ incluindo valores, literatura, política, arte e história. Para ele, esse seria um modo de os Surdos, como uma comunidade organizada, contribuírem para os estudos sobre a diversidade humana. No campo artístico, no caso da surdez, há uma quantidade significativa de ficções - literatura, teatro, cinema, etc. - que relatam essa experiência e a importância da língua de sinais para o grupo. Do mesmo modo, há notadamente um público formado por surdos também interessados nesse tipo de narrativa. Pode-se, por conseguinte, inferir um enorme desejo de sentir-se representado em produções culturais. ${ }^{5}$

\section{"THAT DEAF GUY"}

Matt Daigle é um reconhecido cartunista e ilustrador surdo estadunidense. Antes da criação das tiras em quadrinhos, participou de alguns projetos que almejavam difundir costumes das comunidades surdas em paródias ou sátiras de obras famosas, sobretudo de filmes. ${ }^{6}$ Inspira-se na própria trajetória para construir as tiras, uma vez que há nessas um "cara" surdo utente de língua de sinais, sua esposa ouvinte, que é intérprete/ tradutora, e o filho do casal, uma criança ouvinte e fluente em língua de sinais. Nas tiras em quadrinhos, os personagens centrais são chamados, respectivamente, de Desmond, Helen e Cedric.

Todas as próximas tiras em quadrinhos foram extraídas da página da rede social Facebook chamada @surdalidades. ${ }^{7}$

Tira 1 - That Deaf Guy ${ }^{8}$
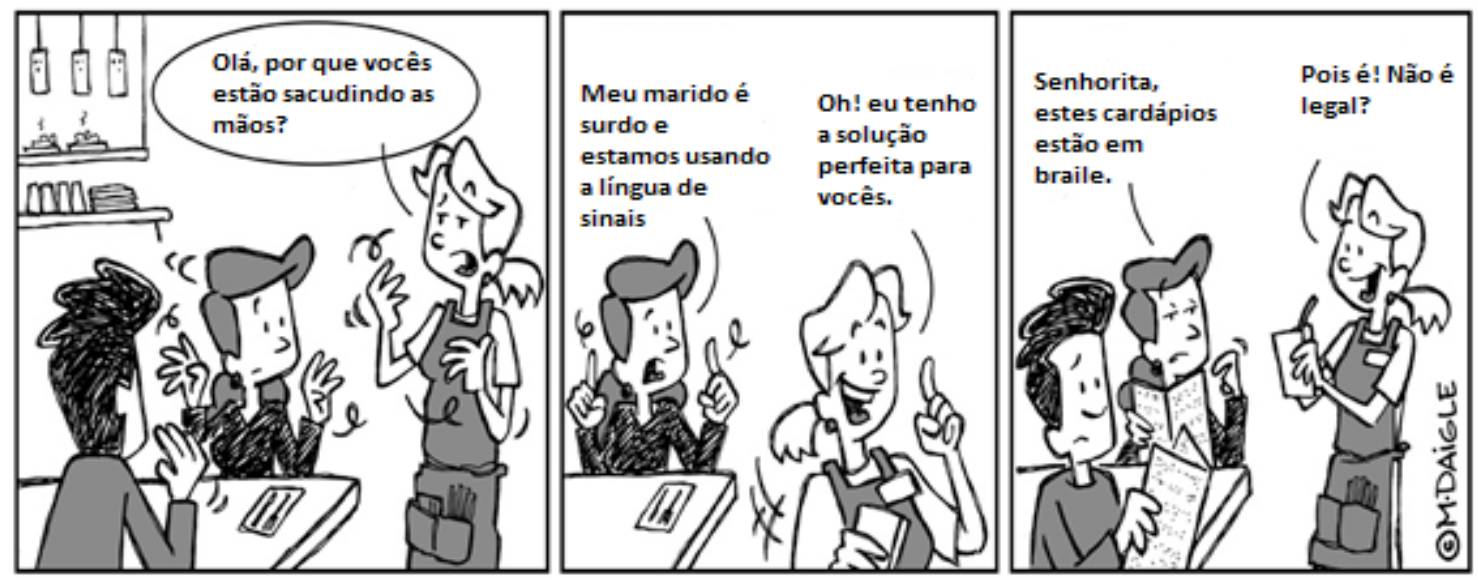

\footnotetext{
${ }^{4} \mathrm{O}$ autor grafa a palavra surdo com um "S" maiúsculo, o que apontaria para uma questão identitária, como um povo específico.

${ }^{5}$ Indicamos um site que dispõe de várias produções culturais de surdos, tanto em filmes, documentários e outras diferentes manifestações artísticas produzidas por surdos: http://culturasurda.net. Acesso em: 19 set 2018.

${ }^{6}$ Disponível em: http://www.deafreel.comhttp://www.deafreel.com. Acesso em: 10 set. 2018.

${ }^{7}$ Disponível em: https://pt-br.facebook.com/pg/surdalidades. Acesso em: 10 set. 2018.

${ }^{8}$ Disponível em: https://www.facebook.com/pg/surdalidades/photos/?tab=album\&album_id=354534317912494. Acesso em: 10 abr. 2019.
} 
A tira $1^{9}$ foi uma das primeiras publicações de "That Deaf Guy", em fevereiro de 2010. Nela, já é possível perceber que a língua de sinais é considerada mero gesto pela garçonete ouvinte, demonstrando claro desconhecimento das especificidades da surdez e, ainda, da cegueira, uma vez que são tratadas como equivalentes e carecendo de uma única forma de acessibilidade: o uso do sistema de escrita táctil conhecido como braile. A língua de sinais - no caso do Brasil, a Libras - e o braile, para muitos leigos, são códigos parecidos que atendem pessoas surdas e pessoas cegas. Tal equívoco é bastante comum, por serem vistas como integrantes de grupos homogêneos; no caso, grupo de deficientes. Trata-se, por conseguinte, de um estigma das deficiências em geral, fenômeno interacional que traz à tona uma condição visível de inferioridade (GOFFMAN, 2008).

O uso da tira 1 em sala de aula é categórica para diferenciar as condições do ser surdo e do ser cego. Pode, portanto, ser usada em classes inclusivas, com alunos surdos e ouvintes, e mesmo nas classes em que não há alunos surdos ainda. $\mathrm{O}$ trabalho a ser feito gira em torno do esclarecimento das especificidades desses sujeitos e das diferentes formas de Ihes propiciar a acessibilidade.Além da linguagem verbal, pode ser destacada a linguagem não verbal realçando, ainda, as expressões faciais dos sujeitos envolvidos.

\section{Tira 2 - That Deaf Guy ${ }^{10}$}

\section{THAT DEAF GUY}

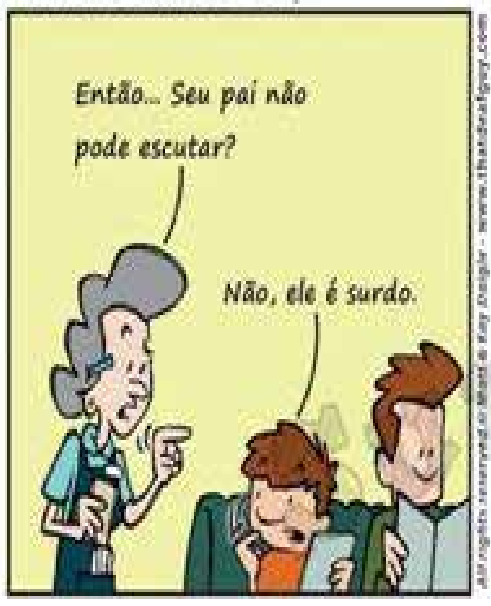

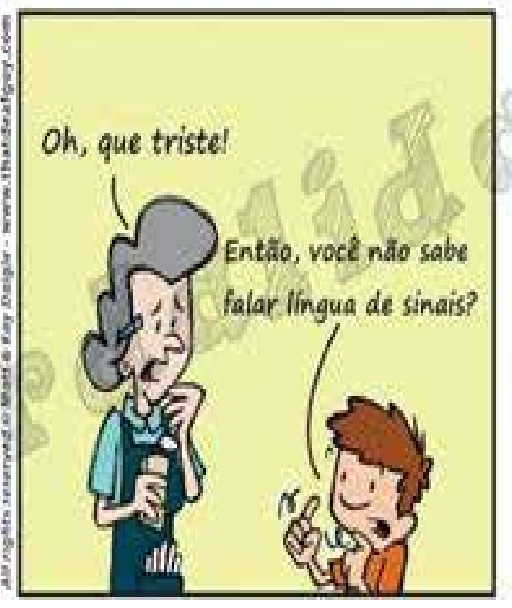

BY MATT \& KAY DAIGLE

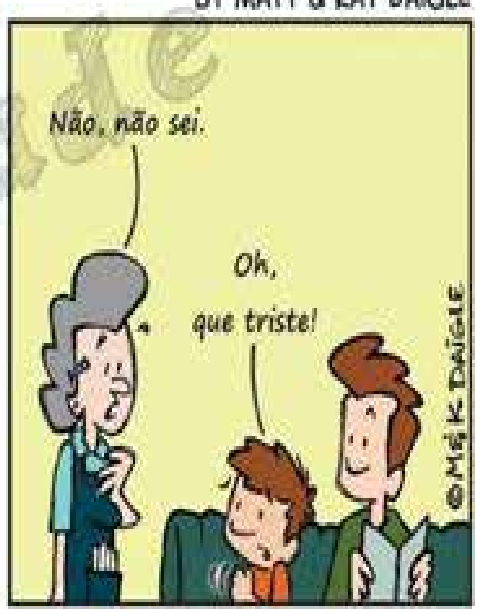

Na tira 2 é nítida a surpresa da senhora que atende Cedric e Desmond ao saber que este é surdo; por outro lado, Cedric relativiza a tristeza dela ao se surpreender por ela não saber língua de sinais. Esta situação traz-nos à tona que a frustração é compartiIhada e oriunda do desconhecimento, ora da surdez de outrem, ora da língua de sinais.

É comum a constatação de que a surdez dificulta aos sujeitos a aquisição espontânea de uma língua oral, exclusivamente, em contato com outras pessoas. Quando nascemos ouvintes, vamos, paulatinamente, constituindo-nos como sujeitos, e faz parte

\footnotetext{
${ }^{9}$ As tiras traduzidas do inglês para o português (os tradutores são voluntários surdos e ouvintes) são encontradas na página do Facebook @surdalidades. Disponível em: https://pt-br.facebook.com/pg/surdalidades. Acesso em: 20 set. 2018.

${ }^{10}$ Disponível em: https://www.facebook.com/surdalidades/photos/a.354534317912494/585009468198310/?type=3\&theater. Acesso em 10 abr. 2019.
} 
desse processo o aprender a falar uma língua oral, sobretudo a partir de estímulos oferecidos por adultos próximos aos novos seres em formação. Com a surdez, no entanto, há um obstáculo para a aquisição da língua oral espontaneamente, o que não ocorre com a língua de sinais. Nesse sentido, os surdos foram considerados deficientes, tendo como base uma impossibilidade de aprender a língua oral de um mesmo modo que os ouvintes, o que se modificou em razão do reconhecimento de seu meio de comunicação visuoespacial: a língua de sinais (PERLIN, 1998).

A tira 2 pode ser utilizada em sala de aula para incentivar os alunos a aprenderem a língua de sinais para que a comunicação seja efetiva com os outros alunos surdos. Além disso, é ainda recorrente o uso errôneo do termo "linguagem" para se referir à língua de sinais no Brasil. Por meio da tira, podemos introduzir a discussão a respeito das diferenças de língua e linguagem, bem como a explicação de que a Libras é uma língua.

\section{THAT DEAF GUY}

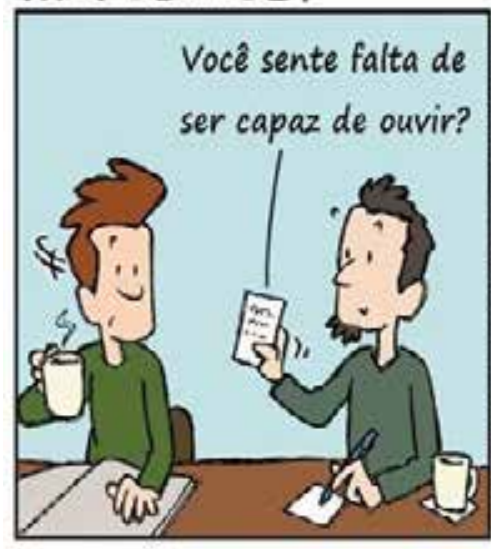

Tira 3 - That Deaf Guy ${ }^{11}$

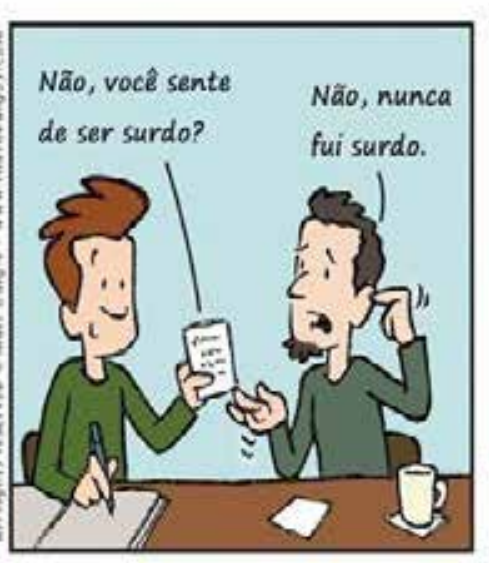

BY MATT \& KAY DAIGLE

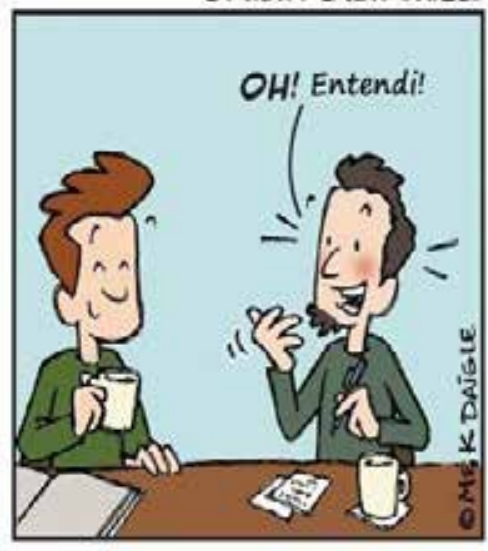

Nas tiras 2 e 3 põe-se em xeque o choque entre o ouvinte e o surdo, embora na tira 2 o choque seja mediado pelo filho, ouvinte, do sujeito surdo, e, na tira 3, o choque aconteça diretamente entre o cara surdo e um ouvinte. Percebe-se que a tira trabalha com a desconstrução do estereótipo de que o surdo sempre será um frustrado por não ouvir. Desmond problematiza ligeiramente isso ao perguntar ao ouvinte se este sente falta de quando era surdo.

Novamente estamos diante de tiras que podem ser usadas em classes com alunos surdos e ouvintes ou classes com alunos ouvintes exclusivamente, uma vez que facilita o desmonte do estereótipo de frustrado em relação ao sujeito surdo e cumpre a proposta inclusiva de aproximar, cada vez mais, surdos e ouvintes. Vale frisar que estamos sugerindo que se trabalhe o choque inicial, a surpresa e as ideias preconcebidas em geral a respeito da condição dos surdos. É possível, ainda, destacar com os estudantes o uso da interjeição associada à expressão facial do ouvinte no terceiro quadrinho, quando compreende, finalmente, que é estranho sentir falta do que nunca foi.

\footnotetext{
${ }^{11}$ Disponível em: https://www.facebook.com/surdalidades/photos/a.354534317912494/362269503805642/?type=3\&theater. Acesso em: 10 abr. 2019.
} 
THAT DEAF GUY
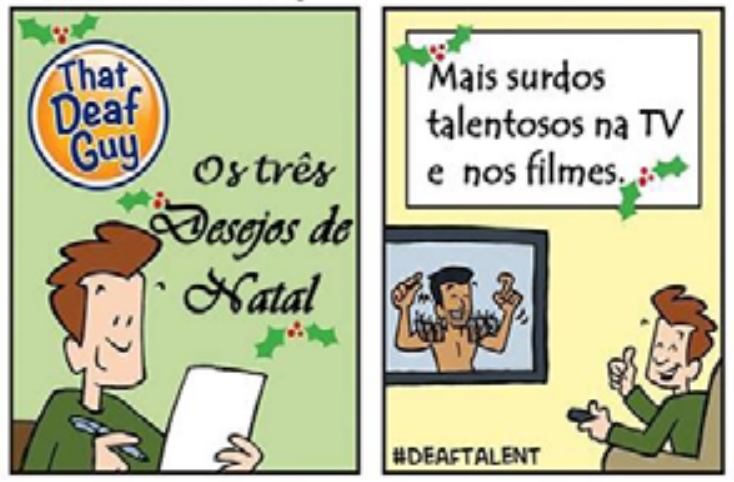

BY MATT \& KAY DAIGLE

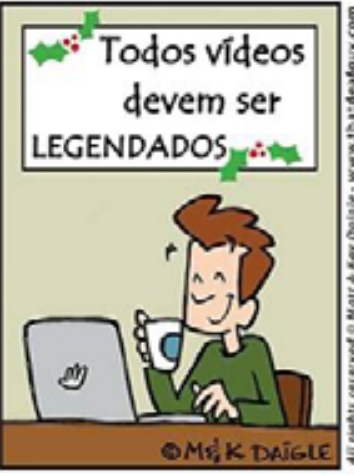

Que os médicos

saibam a

comunicar em Libras

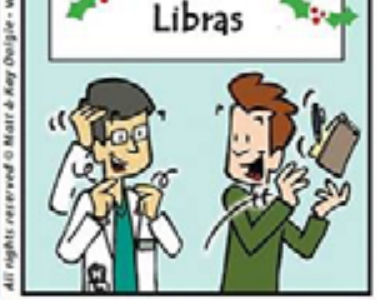

A tira 4 mostra claramente os desejos de Natal do Desmond, não recaindo sobre bens materiais. Fica evidente que ele pede acessibilidade e dá exemplos: presença de sujeitos surdos na televisão e no cinema, vídeos com legendas e profissionais de saúde que saibam comunicar-se em língua de sinais. Tais pedidos denunciam que são medidas plausíveis para a acessibilidade dos surdos, mas que não são tomadas.

No caso da comunidade surda, há várias reivindicações, dentre as quais as principais são: a presença de intérpretes/tradutores de língua de sinais/português em todos os espaços e, além disso, uma qualificação das pessoas que têm contato com esse público de modo a conseguir comunicar-se, solicitar e responder informações básicas em língua de sinais. Reivindica-se também a presença de mediadores surdos que atuem em espaços como museus e bibliotecas, por exemplo, como contadores de histórias em língua de sinais, entre diversas outras possibilidades. No caso do Brasil, há também a solicitação rotineira de legendas em língua portuguesa ou em Libras para a produção audiovisual, que, ainda hoje, é inacessível à maioria dos sujeitos surdos. Tais vivências culturais são fundamentais para a construção da cidadania do surdo, e a escola torna-se um espaço privilegiado, muitas vezes o único, para que esses estudantes tenham contato com diferentes produções artísticas.

No tocante à cultura, podemos analisar o Plano Nacional de Cultura (GRAEFF; FERNANDES; CLOSS, 2013). Nele, percebemos que desde, pelo menos, os anos 80 , há uma diversidade de medidas públicas que visam a promover a inserção de diferentes grupos em diversas esferas culturais. Fala-se, por exemplo, de "acessibilidade cultural", "equipamentos culturais" e "ambientes culturais". De acordo com o plano, acredita-se que

[...] a perspectiva segundo a qual todo cidadão brasileiro tem o direito de participação livre na vida cultural de sua comunidade, bem como de fruir das artes e das ciências e produzi-las, vendo assegurada a proteção de seus interesses morais e materiais vinculados a essas produções intelectuais (GRAEFF; FERNANDES; CLOSS, 2013, p. 119).

\footnotetext{
12Disponível em: https://www.facebook.com/surdalidades/photos/a.354534317912494/1101977513168167/?type=3\&theater. Acesso em: 10 abr. 2019.
} 
Os autores alertam para a necessidade de se pensar como passar das políticas de compensação para as de emancipação dos grupos atendidos. Isso porque demanda "a tomada de consciência não apenas dos direitos de acesso, fruição e criação da cultura, mas do aspecto cidadão que implica o reconhecimento intersubjetivo do outro e das diferenças culturais" (GRAEFF; FERNANDES; CLOSS, 2013, p. 120). Com efeito, podemos perceber que nem sempre foi possível ou desejável que a experiência estética estivesse disponível para grupos antes pouco habituados a essa possibilidade. Museus, bibliotecas e vários espaços considerados artístico-culturais são praticamente inacessíveis para determinados grupos sociais, seja como possibilidade de fruição, seja como possibilidade de produção. Com isso, podemos pensar na arte também como um gesto de intervenção do sujeito na comunidade, alterando ou, ao menos, expandindo essa possibilidade de experimentação cultural.

Do mesmo modo, podemos perceber uma tentativa de determinados grupos intervirem nesses regimes estéticos que deveriam ser comuns, buscando também uma produção de novos regimes de visibilidade, ou seja, propor novas formas de poder contar suas histórias. Isso inegavelmente corresponde à ideia de que há uma necessidade de criar novas possibilidades de "escuta" para vozes que se encontram "às margens" dos sistemas de representação.

A partir da tira 4, os alunos podem elaborar as próprias listas de desejo, percebendo se suas principais questões estão em bens materiais, no campo das emoções, na seara espiritual, na reivindicação de um mundo mais acessível a todos, etc. Pode-se comparar a própria lista elaborada com a feita por Desmond, refletindo sobre os motivos que levam o pai do Cedric a sonhar com questões que podem parecer tão simples para os ouvintes. Por fim, é possível comentar com os alunos as causas da expressão facial de alegria do personagem em todos os quadrinhos dessa tira.

\section{Tira 5 - That Deaf Guy ${ }^{13}$}

\section{THAT DEAF GUY}

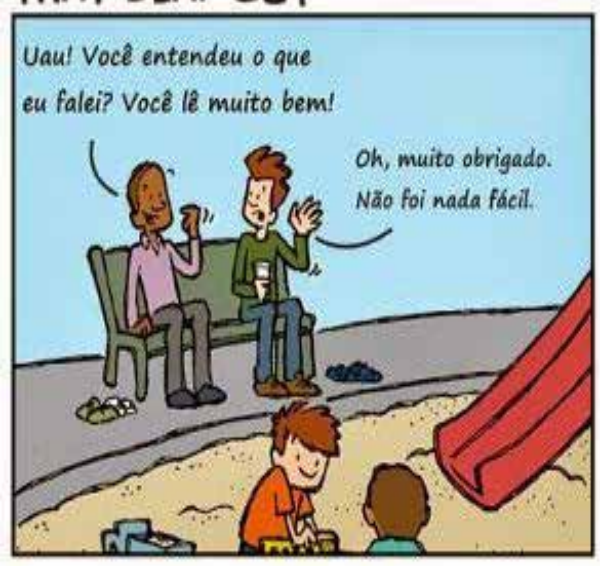

BY MATT \& KAY DAIGLE

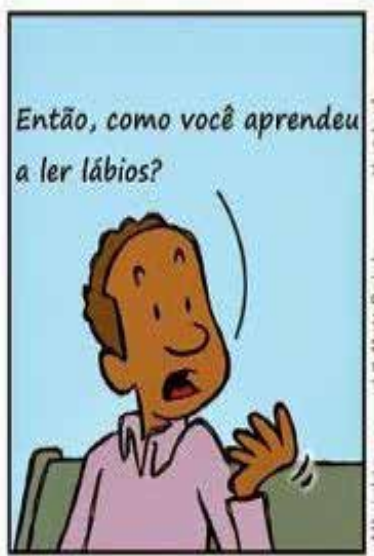

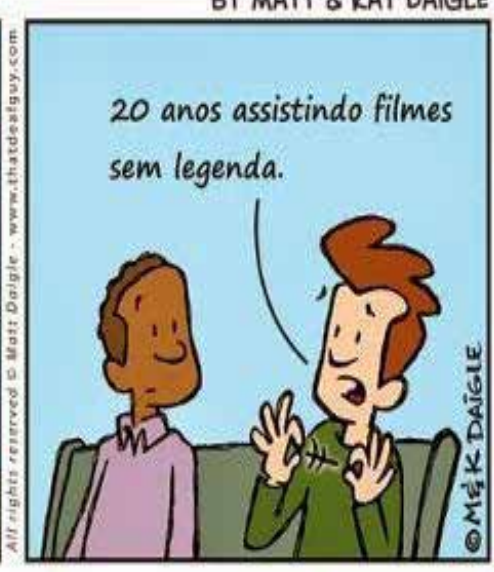

${ }^{13}$ Disponível em: https://www.facebook.com/surdalidades/photos/a.354534317912494/366666893365903/?type=3\&theater. Acesso em: 10 abr. 2019. 
A tira 5 traz outro estereótipo relacionado à pessoa surda: a leitura de lábios. Desmond mostra para seu interlocutor que aprendeu a fazer leitura labial ou orofacial, pois, por anos, assistiu a filmes sem legenda. Há o estereótipo de que o sujeito surdo compreende tudo que é pronunciado em linguagem oral - alguns ouvintes chegam a falar pausadamente ou aumentando a altura da voz, acreditando que, assim, os surdos entenderão o que está sendo falado. Vale frisar que a leitura labial ou orofacial consiste na habilidade de ler os lábios e expressões faciais intuindo o que pode estar sendo dito na linguagem oral. Para Sacks (1998, p. 15), o termo "leitura labial" é inadequado para designar "a complexa arte de observação, inferência e adivinhação inspirada dessa tarefa". Nem toda pessoa surda consegue fazê-la efetivamente. Não se trata de habilidade inata: "todos os estudos referentes à leitura labial estão vinculados aos treinamentos fono-articulatórios e é nesse sentido que poderíamos afirmar que não se trata de uma habilidade natural de linguagem" (GESSER, 2009, p. 60-61). Não é todo surdo, portanto, que faz leitura labial com êxito, uma vez que nem todos foram sistematicamente ensinados por fonoaudiólogos a fazê-lo ou aprenderam, como o Desmond, apenas vendo filmes sem legendas.

A inserção dessa tira em sala de aula desconstrói o estereótipo do surdo como leitor de lábios e estimula os alunos não surdos a aprenderem a língua de sinais, em vez de tentarem falar pausadamente ou aumentando a altura da voz diante do sujeito surdo que não usa sequer aparelho auditivo ou porta implante coclear. Incentivar que os ouvintes aprendam Libras é fundamental para garantir, futuramente, a inclusão no meio socioeducacional que se espera para os surdos. Infelizmente, a Libras ainda é pouco ensinada aos ouvintes. Estes, por sua vez, raramente a procuram, mesmo que, hoje, se fale tanto na emergência do profissional intérprete e tradutor de Libras/língua portuguesa no mercado de trabalho. Felizmente, vemos a procura por cursos de Libras em nível de extensão, Graduação e Pós-Graduação aumentar pela força da Lei de Libras, mas a busca ainda está aquém do que os sujeitos surdos necessitam.

\section{THAT DEAF GUY}

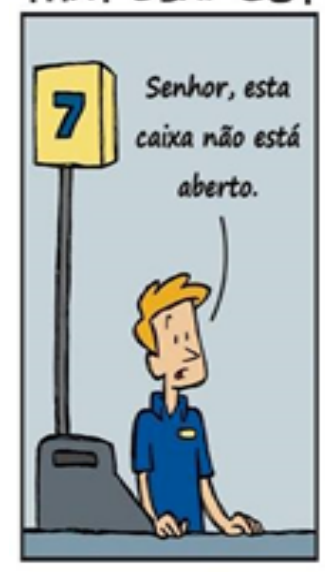

Tira 6 - That Deaf Guy ${ }^{14}$

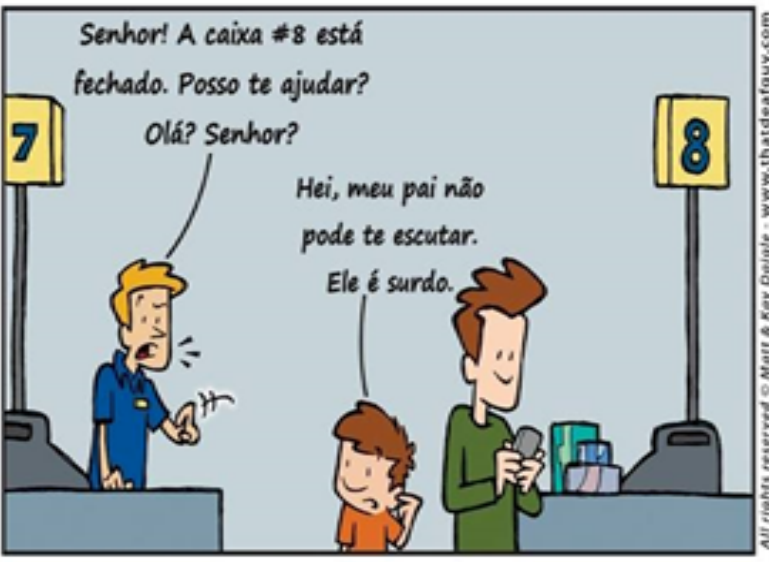

BY MATT \& KAY DAIGLE

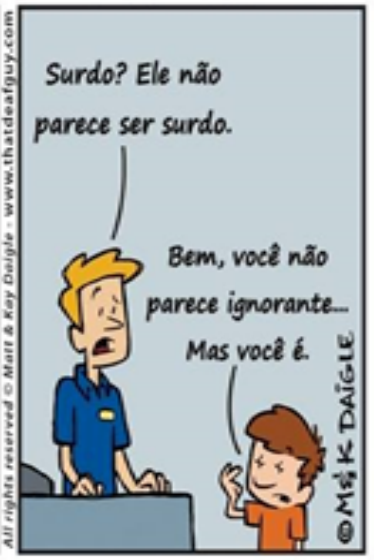

\footnotetext{
14Disponível em: https://www.facebook.com/surdalidades/photos/a.354534317912494/1017440911621828/?type=3\&theater. Acesso em: 10 abr. 2019.
} 
A tira 6 traz à tona a questão do estigma invisível da surdez, pois o caixa parece não acreditar que o Desmond é surdo, ao contrário do que diz Cedric. O menino, como faz em muitas tiras, em tom educativo, evidencia aos demais que o pai é surdo, mas, via de regra, vê-se obrigado a mudar o tom para o deboche, posto que nem sempre tem dos ouvintes a compreensão da surdez que espera.

Em sala de aula a tira 6 pode ser usada para mostrar meios possíveis de se chamar a atenção do sujeito surdo sem ser pela altura da voz, como com o toque. Também pode ser comentado que a pessoa surda está em todos os lugares, não somente na escola, e que a acessibilidade para ela nem sempre é pensada. Com isso, pode-se solicitar aos alunos que sugiram formas de melhorar e facilitar a vida em sociedade desse sujeito, frisando que, infelizmente, nem todos os brasileiros sabem Libras, embora muitos façam cursos de idiomas como inglês, espanhol, francês, mandarim, dentre outros. É possível refletir com os alunos - até mesmo para estimular uma produção textual - os motivos pelos quais a Libras não tem, ainda, reconhecimento e valorização social se comparada a outras línguas. Trata-se meramente de aprender idiomas com vistas a ampliar a comunicação com o mundo ou de aprender línguas largamente valorizadas para ampliar o status social? Essas são algumas das reflexões possíveis de serem trilhadas em sala de aula, em disciplinas as mais variadas.

\section{Tira 7 - That Deaf Guy ${ }^{15}$}

\section{THAT DEAF GUY}

BY MATT \& KAY DAIGLE

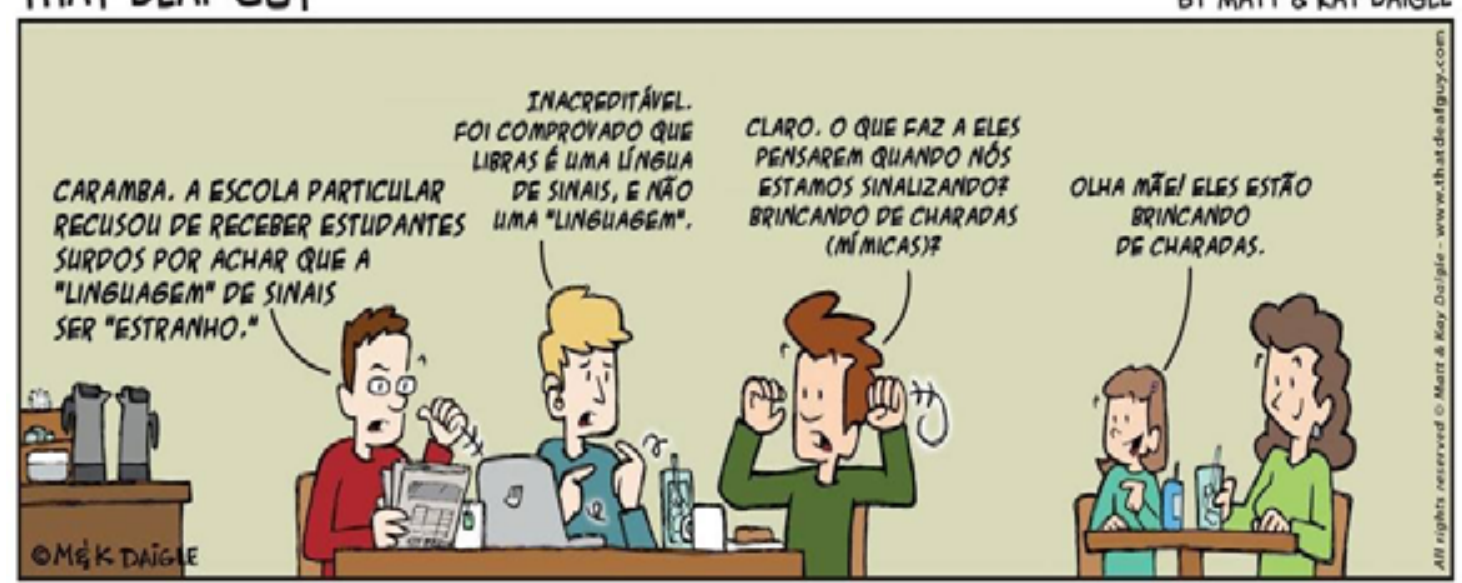

A tira 7 traz estereótipos relacionados à língua de sinais, além de mostrar um grave problema da rede escolar: a recusa à matrícula do aluno surdo, mesmo em tempos de inclusão educacional. Considerar a língua de sinais linguagem parece lugar comum entre ouvintes leigos, que, via de regra, seguem acreditando que os surdos fazem mímicas - como a menina fala à sua mãe.

Gesser (2009) elenca alguns estereótipos que envolvem a língua de sinais: universal, artificial, desprovida de gramática própria, mímica, não exprimiria conceitos abstratos, seria exclusivamente icônica, código secreto dos sujeitos surdos; apenas o alfabeto

${ }^{15}$ Disponível em: https://www.facebook.com/surdalidades/photos/a.354534317912494/966689483363638/?type=3\&theater. Acesso em: 10 abr. 2019. 
manual, uma versão sinalizada da língua oral e teria origem histórica nesta, não apresentaria variações linguísticas e seria ágrafa. São equívocos em relação à Libras. Alguns desses mitos acabam dando força ao preconceito a sujeitos surdos sinalizadores. A Libras sempre sofreu preconceito no aspecto da resistência linguística dos sujeitos surdos (DINIZ, 2011).

Cumpre esclarecer que "as línguas de sinais são, portanto, consideradas pela linguística como línguas naturais ou como um sistema linguístico legítimo e não como um problema do surdo ou como uma patologia da linguagem" (QUADROS; KARNOPP, 2004, p. 30). O estudo de William Stokoe (1960) comprovou que a língua de sinais é uma língua genuína e que os sinais consistem em símbolos abstratos complexos, portando uma complexa estrutura interior; não se trata de gestos.

Em sala de aula, a tira 7 pode ser usada para elucidar os estudantes sobre as diferenças entre língua e linguagem e mostrar que a língua de sinais não é mímica, como muitos podem acreditar. No caso de turmas em que haja alunos surdos e ouvintes, uma sugestão é deixar que os surdos conversem espontaneamente em língua de sinais e, depois, pedir aos ouvintes que digam o que entenderam da conversa, com a finalidade de mostrar que não se trata de uma brincadeira de mímica, mas de uma língua de fato.

Tira 8 - That Deaf Guy ${ }^{16}$

THAT DEAF GUY

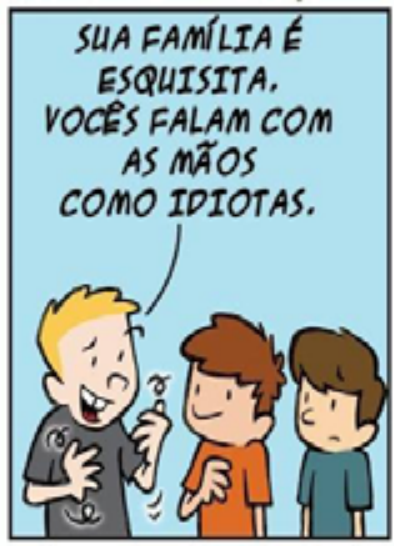

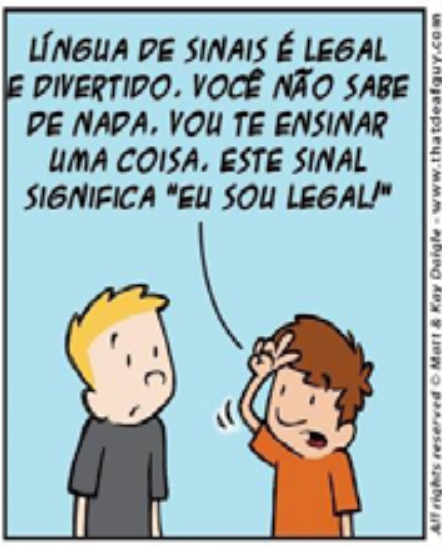

BY MATT \& KAY DAIGLE

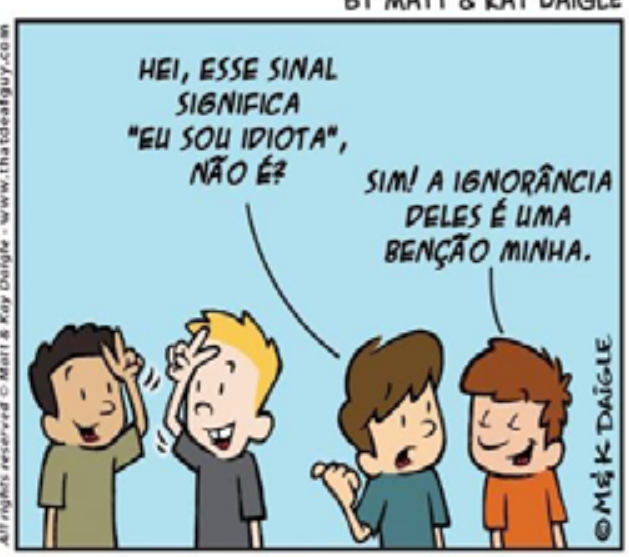

A tira 8 traz exemplo de preconceito contra a língua de sinais e a pessoa surda. Vemos que o menino loiro chama a família do Cedric de esquisita por usar as mãos como "idiotas". Cedric responde afirmando que é a língua de sinais - marcando que é uma língua -, legal e divertida, e propõe-se a ensinar um sinal ao colega. O humor da tira reside na constatação de que o sinal ensinado não corresponde ao que foi dito anteriormente, mostrando que o menino sempre debocha dos ouvintes que desprestigiam a língua de sinais. Mais uma vez Cedric denuncia a ignorância como uma das possíveis fontes do preconceito.

\footnotetext{
${ }^{16}$ Disponível em: https://www.facebook.com/surdalidades/photos/a.354534317912494/1017443511621568/?type=3\&theater. Acesso em: 10 abr. 2019.
} 
Em sala de aula a tira 8 pode ser utilizada para descontruir preconceitos em relação ao sujeito surdo e à língua de sinais, problematizando os motivos de se considerar esquisito ou engraçado aquilo que, no fundo, se ignora. Deve-se, ainda, mostrar que palavras podem desrespeitar e ferir e, por isso, chamar a família de alguém de esquisita, por ser ela diferente do que se costuma ver, pode magoar outra pessoa ou, ainda, fazer com que se receba dela uma resposta como a de Cedric.

\section{Tira 9 - That Deaf Guy ${ }^{17}$}

THAT DEAF GUY

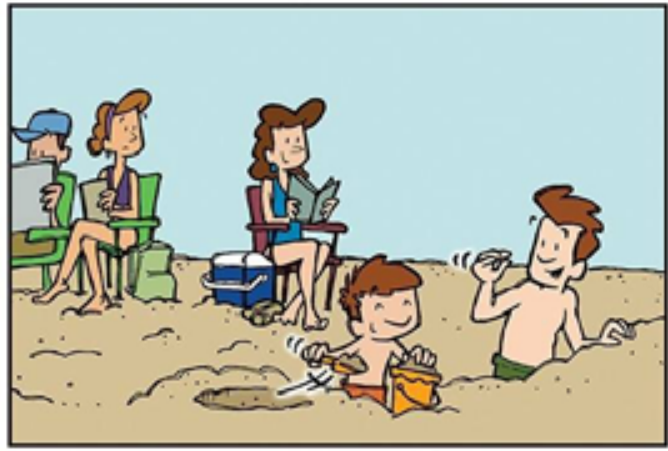

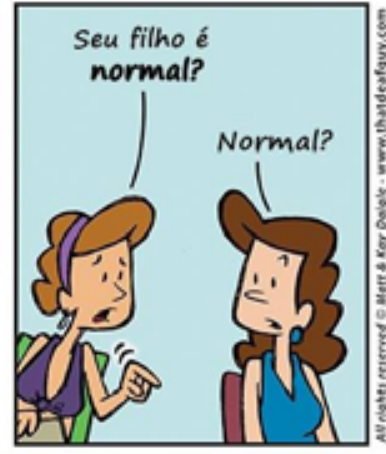

Se ele é surdo

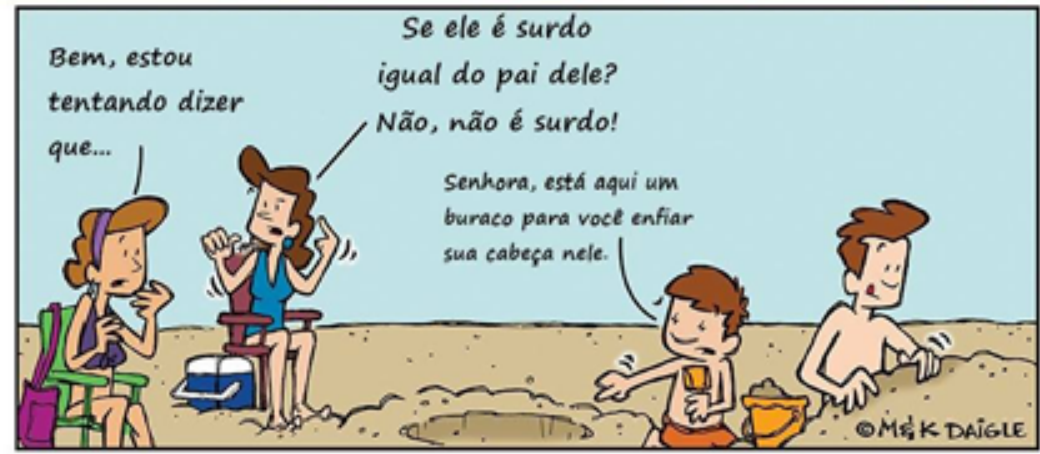

BY MATT \& KAY DAIGLE

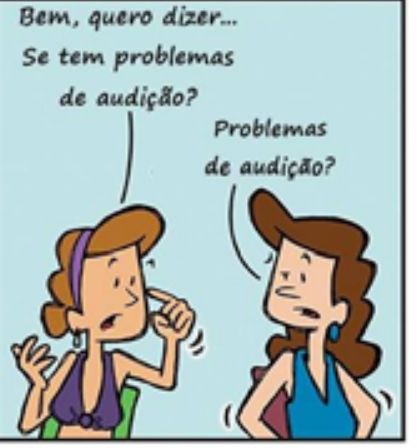

Os quadrinhos da tira 9 trazem estereótipos e preconceitos contra a pessoa surda, vista como anormal, defeituosa, problemática, alguém que carece de audição. Peregrino $(2015,2018)$ discute a respeito disso e demonstra que o viés clínico-terapêutico, mesmo que considerado ultrapassado hoje, em relação ao modo de se ver o sujeito surdo, ainda prevalece fora das comunidades surdas. As pessoas, em geral, seguem vendo os surdos como aqueles a quem falta algo, nos quais há uma lacuna a ser preenchida (medicalizada), e não como sujeitos da própria história, integrantes de uma minoria linguística, usuários da língua de sinais e de uma cultura própria. Cedric, mais uma vez, promove o desfecho, mostrando que a mulher com que sua mãe conversa passou por vergonha. Cumpre frisar que a interlocutora de Helen não sabe como se referir ao menino que, segundo pensava, seria um surdo. Mostra, com isso, não somente o desconhecimento em si do termo "surdo" como mais adequado, mas evidencia a suposta necessidade de eufemismos para atenuar a ideia da surdez - ainda que os usados tenham soado mais desagradáveis ainda a Helen e Cedric.

${ }_{17}$ Disponível em: https://www.facebook.com/surdalidades/photos/a.354534317912494/1054378001261452/?type=3\&theater. Acesso em :10 abr. 2019. 
Em sala de aula esses quadrinhos podem ser problematizados para mostrar os termos adequados para se referir aos sujeitos surdos e aqueles considerados pejorativos e, mesmo, preconceituosos, em relação à condição surda. Cabe, também, mostrar aos alunos que o surdo não é alguém a quem falta algo, mas alguém que usa outra forma de expressão e comunicação e que nem por isso deve ser discriminado ou ridicularizado. Pedir aos alunos a produção de um texto sobre isso é relevante. Podem até mesmo construir quadrinhos em que coloquem personagens surdos dialogando sobre o que pensam do que falam os ouvintes a seu respeito. Por outro lado, é possível pedir aos alunos surdos que comentem tudo que os ouvintes já disseram sobre eles na condição de sujeitos surdos.

\section{Tira 10 - That Deaf Guy ${ }^{18}$}

THAT DEAF GUY

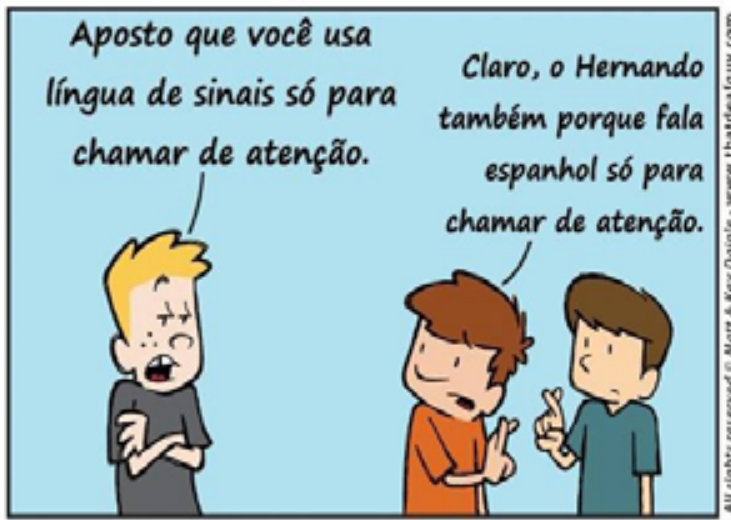

BY MATT \& KAY DAIGLE

$$
\text { Bah! Mas ele Bem... Então tem alguma }
$$
nasceu e cresceu diferença se meu pai é surdo? falando espanhol. Agora vou esperar até

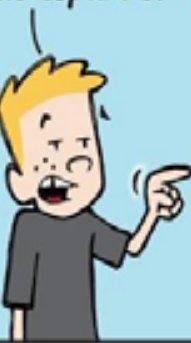

aparecer a luz

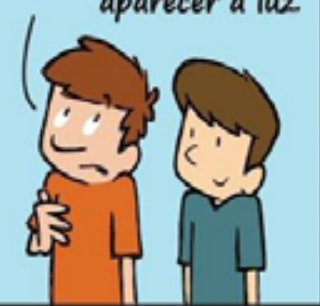

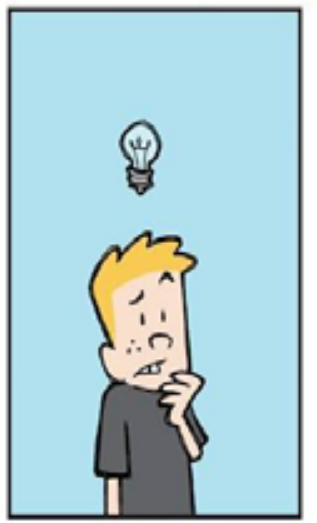
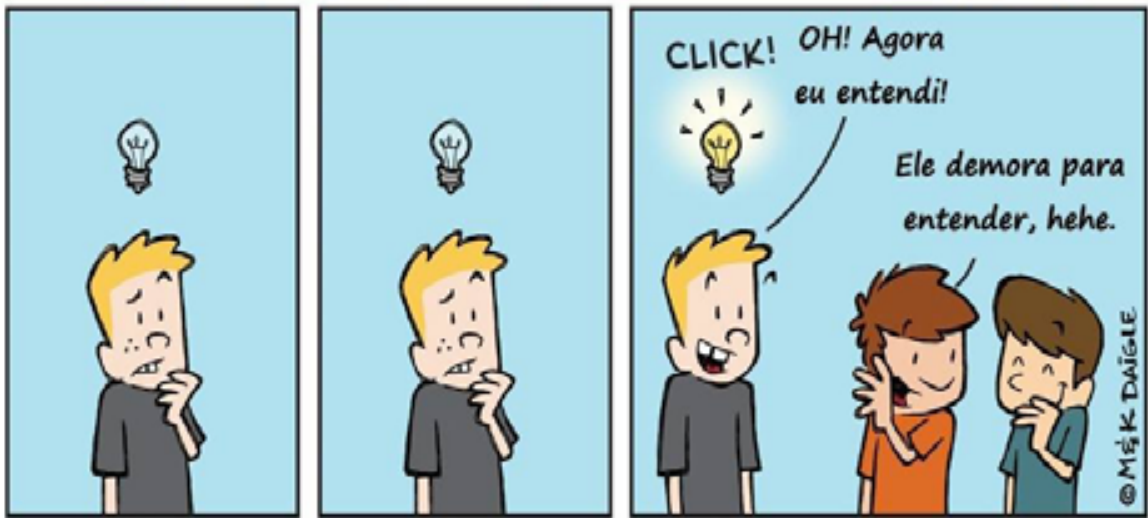

Por fim, os quadrinhos da tira 10 trazem estereótipos e preconceitos contra a língua de sinais e a pessoa surda. O menino loiro acha que Cedric usa a língua de sinais para chamar a atenção, entretanto o filho de Desmond e Helen lembra que outro menino, o Hernando, deve falar espanhol apenas para chamar a atenção também. O menino conclui que o Hernando nasceu e cresceu falando a língua espanhola e demora a perceber que, com Cedric, dá-se o mesmo em relação à língua de sinais. Por serem carregadas de expressividade, as línguas de sinais, não raramente, chamam a atenção dos ouvintes que com elas se deparam, mas cabe o esclarecimento de que tal é próprio

\footnotetext{
${ }^{18}$ Disponível em: https://www.facebook.com/surdalidades/photos/a.354534317912494/1017443511621568/?type=3\&theater. Acesso em: 10 abr. 2019.
} 
da língua, como a entonação ocorre nas línguas orais. Além disso, podemos pensar em atividades que utilizem a produção de tiras em quadrinhos, seja por meio do uso de desenho produzido pelos próprios alunos, seja pelo uso de fotografias, com a utilização de programas simples para edição de imagens. É bastante comum o interesse dos alunos em relatar situações semelhantes. Tendo como base esses relatos, o professor pode promover condições que possibilitem a tais alunos a exposição de suas produções autorais.

Assim, em sala de aula, esses quadrinhos, e todos os demais do "That Deaf Guy", podem ser utilizados para mostrar aos alunos, sejam surdos, sejam ouvintes, a importância do respeito à pessoa surda e à língua de sinais. Compreender que o que diferencia surdos e ouvintes pode ser a língua de comunicação e expressão e os recursos a ela associados, já é um passo dado para a inclusão socioeducacional sem preconceitos e estereótipos.

\section{CONSIDERAÇÕES FINAIS}

A inclusão sistemática de textos escritos por sujeitos surdos proporciona uma perspectiva intercultural para o ensino-aprendizagem, valorizando diferentes formas de expressão com a inserção de temáticas próprias do campo da surdez, como modo de ressignificar a representação do surdo.

Os quadrinhos "That Deaf Guy" trazem à luz não apenas uma produção pelo viés do próprio sujeito da experiência, mas também temáticas caras à comunidade, à cultura e à língua de sinais. Assim, o uso, na escola, desse gênero textual - exemplificado com as histórias de Desmond, Helen e Cedric - propicia a reflexão da interculturalidade, da inclusão, da acessibilidade, além de poder enriquecer questões mais específicas da linguagem escrita. Atende, portanto, não somente às aulas de línguas, mas também às de outras que favoreçam a incansável e persistente problematização de estereótipos e preconceitos.

Além disso, ressaltamos sempre a possibilidade de utilizar, no decorrer da educação básica de alunos surdos e não surdos, textos produzidos ou valorizados na/pela comunidade surda nas diferentes disciplinas, como forma de propiciar o contato com diferentes representações da surdez, possibilitando uma identificação com o que é ensinado. A língua portuguesa escrita ainda é considerada um desafio para estudantes surdos dos diferentes segmentos; assim, aproximá-los de artefatos culturais que tematizem a surdez pode despertar o interesse para o engajamento da leitura e escrita da segunda língua.

Pensando em uma escola que se quer inclusiva para todos - e também para os surdos -, as reflexões tecidas aqui devem ser frequentes para que alunos e professores tenham um contato mais significativo com diferentes experiências estéticas e literárias que formam nossos aparatos culturais - principalmente em um país que tem oficializadas, até o momento, duas línguas: a língua portuguesa e a língua brasileira de sinais. 


\section{conterts \\ \&Educaçăo}

\section{REFERÊNCIAS}

ARENDT, Hannah. A promessa da política. 4. ed. Rio de Janeiro: Difel, 2012.

BAUMAN, H-D. L. Introduction: Listening to deaf studies. In: BAUMAN, H-Dirksen L. (org.). Open your eyes: Deaf studies talking. Minneapolis: University of Minnesota, 2008.

BENJAMIN, Walter. O narrador. Considerações sobre a obra de Nikolai Leskov. In: Obras Escolhidas I. Magia e técnica, arte e política. São Paulo: Brasiliense, 1996.

BRASIL. Lei no 10.436, de 24 de abril de 2002. Dispõe sobre a Língua Brasileira de Sinais - Libras - e dá outras providências.

CANDAU, Vera. Sociedade multicultural e educação: tensões e desafios. In: CANDAU, Vera. Cultura(s) $e$ educação: entre o crítico e o pós-crítico. Rio de Janeiro: DP\&A, 2005.

CANDAU, Vera. Sociedade, educação e cultura(s): questões e propostas. 3. ed. Petrópolis, RJ: Vozes, 2010. DINIZ, Heloise Gripp. A história da língua de sinais dos surdos brasileiros: um estudo descritivo de mudanças fonológicas e lexicais da Libras. Petrópolis, RJ: Arara Azul, 2011.

DORTIER, Jean-François. Dicionário de ciências humanas. São Paulo: Editora WMF Martins Fontes, 2010. GESSER, Audrei. Libras? Que língua é essa? Crenças e preconceitos em torno da língua de sinais e da realidade surda. São Paulo: Parábola Editorial, 2009. (Estratégias de ensino; 14).

GOFFMAN, Erving. Estigma: notas sobre a manipulação da identidade deteriorada. 4. ed. Rio de Janeiro: LTC, 2008.

GRAEFF, Lucas; FERNANDES, Maria Castilhos; CLOSS, Anajara Carbonell. Acessibilidade em ambientes culturais: explorando o potencial cidadão do plano nacional de cultura. SER Social, Brasília, v. 15, n. 32, p. 117-140 jan./jun. 2013.

JODELET, Denise. Os processos psicossociais da exclusão. In: SAWAIA, Bader (org.). As artimanhas da exclusão: análise psicossocial e ética da desigualdade social. 13. ed. Petrópolis: Vozes, 2013. p. 55-67.

MAHER, T. M. A educação do entorno para a interculturalidade e o purilinguismo. In: KLEIMAN, A. B.; CAVALCANTI, M. C. (org.). Linguística aplicada: faces e interfaces. Campinas, SP: Mercado das Letras, 2007.

PATROCINIO, Paulo Roberto Tonani do. Escritos à margem: a presença de autores de periferia na cena literária brasileira. Rio de Janeiro: 7Letras; Faperj, 2013.

PEREGRINO, Giselly. Secreto e revelado, tácito e expresso: o preconceito contra/entre alunos surdos. 2015. 247p. Tese (Doutorado em Ciências Humanas - Educação) - Pontifícia Universidade Católica do Rio de Janeiro, Rio de Janeiro, 2015.

PEREGRINO, Giselly. Preconceito e educação: desafios à escolarização de surdos no século XXI. Curitiba: CRV, 2018.

PERLIN, G. T. T. Identidades surdas. In: SKLIAR, C. (org.). A surdez: um olhar sobre as diferenças. Porto Alegre: Editora Mediação, 1998.

QUADROS, Ronice Müller de; KARNOPP, Lodenir Becker. Língua de sinais brasileira: estudos lingüísticos. Porto Alegre: Artmed, 2004.

SACKS, Oliver. Vendo vozes: uma viagem ao mundo dos surdos. São Paulo: Companhia das Letras, 1998. SILVA, A. G. Por uma poética dos sentidos: a literatura no contexto da surdez. 2016. 167f. Dissertação (Mestrado em Letras) - Pontifícia Universidade Católica do Rio de Janeiro, Departamento de Letras, Rio de Janeiro, 2016.

STOKOE, William. Sign Language Structure. Silver Printing: Linstok Press, 1960. 